\title{
Elisabetta Mastrogiacomo, Libertinismo e Lumi. André-François Boureau-Deslandes (1689-1757)
}

\section{Marisa Ferrarini}

\section{(2) OpenEdition}

1 Journals

\section{Edizione digitale}

URL: http://journals.openedition.org/studifrancesi/5635

DOI: 10.4000/studifrancesi.5635

ISSN: 2421-5856

\section{Editore}

Rosenberg \& Sellier

\section{Edizione cartacea}

Data di pubblicazione: 1 septembre 2011

Paginazione: 410-411

ISSN: 0039-2944

\section{Notizia bibliografica digitale}

Marisa Ferrarini, «Elisabetta Mastrogiacomo, Libertinismo e Lumi. André-François Boureau-Deslandes (1689-1757)», Studi Francesi [Online], 164 (LV | II) | 2011, online dal 30 novembre 2015, consultato il 09 janvier 2021. URL: http://journals.openedition.org/studifrancesi/5635 ; DOI: https://doi.org/10.4000/ studifrancesi.5635

Questo documento è stato generato automaticamente il 9 janvier 2021.

\section{(c)}

Studi Francesi è distribuita con Licenza Creative Commons Attribuzione - Non commerciale - Non opere derivate 4.0 Internazionale. 


\title{
Elisabetta Mastrogiacomo, Libertinismo e Lumi. André-François Boureau-Deslandes (1689-1757)
}

\author{
Marisa Ferrarini
}

\section{NOTIZIA}

eLISABETTA MASTROGiaComo, Libertinismo e Lumi. André-François Boureau-Deslandes

(1689-1757), Napoli, Liguori editori, 2009, 356 pp.

1 Alla controversa questione se vi sia continuità o meno tra il pensiero libertino e la filosofia dei Lumi, Elisabetta Mastrogiacomo risponde con un volume ponderoso dedicato ad André-François Boureau-Deslandes, scienziato e filosofo settecentesco dalle mille sfaccettature. Che il lavoro di ricerca sia serio e sia costato anni di fatica lo dimostra una bibliografia di cinquantuno pagine (pp. 299-350).

2 La difficoltà maggiore è ovviamente consistita nel muoversi in un magma di scritti inediti, autentici e apocrifi, sovente pubblicati in anonimato. Ciononostante l'A. è riuscita a ricostruire l'itinerario intellettuale di Boureau-Deslandes, proponendoci un'analisi della sua produzione in ordine cronologico e tematico, «classificando i testi in storici, filosofici, poetici, scientifici economici, politici» (p. 3).

3 L'esame in concreto di una figura come quella di Boureau-Deslandes, afferma Gianni Pagamini nella «Premessa», «mostra l'intreccio, si direbbe inestricabile, di motivi libertini e di audacie illuministiche, senza che l'autore abbia mai avvertito una reale cesura fra gli uni e le altre» (p. X). Ne risulta una lettura affascinante. In particolare colpiscono testi come il Pigmalion ou la Statue animée del 1741, reinterpretazione in chiave filosofico-materialistica del mito greco del leggendario re di Cipro, in cui Boureau-Deslandes elabora, per la prima volta (tredici anni prima del noto trattato di Condillac del 1754), una teoria della conoscenza che attraverso il paradigma della statua animata individua nei processi della sensazione l'origine di tutte le cognizioni 
umane. Il Recueil de différens traités de Physique et d'Histoire naturelle, del 1736, è una raccolta di memorie e trattati filosofici, accompagnata da una dettagliata analisi di esperimenti eseguiti dall'autore stesso, in cui Boureau-Deslandes difende a spada tratta il metodo newtoniano, stabilendo i principi della fisica sperimentale (osservazione, sperimentazione, conclusione), evitando di accogliere ragionamenti che colpiscono troppo l'immaginazione. Lo stimolo alla ricerca attraverso un dubitare continuo, senza stabilire alcun sistema, può essere tranquillamente applicato alla filosofia. Il metodo sperimentale "aiuta l'ingegno a non perdersi in vane speculazioni metafisiche, a considerare l'oggetto d'indagine secondo i principi di una vera e propria "Philosophie Expérimentale"» (p. 104). Di filosofia per l'appunto si tratta nell' Histoire critique de la Philosophie (1737). È la prima storia della filosofia scritta in francese che precede di cinque anni la Historia critica del tedesco Brucker redatta ancora in latino (1742-1744), segnando la fine del metodo di ricerca filologico-dossografico, tipico della storiografia erudita del Seicento e del Settecento, con l'adozione di un metodo d'indagine critico nell'esposizione delle dottrine filosofiche del passato, che deve tener conto dei contesti storico-culturali e politico-sociali in cui date filosofie si sono sviluppate. L'attenzione rivolta alla tematica culturale e alla comprensione del comportamento umano si accompagna, in Boureau-Deslandes, ad un sincero rispetto per la diversità e la peculiarità di ciascuno, sino ad arrivare ad un'esplicita difesa della tolleranza contro il fanatismo religioso e all'apologia dell'ateismo. Proprio in questo testo trova conferma il tema della doppia verità, tanto caro al libertinismo militante con la sua dissociazione tra pubblico e privato, la sua predilezione per la velata circolazione delle idee. E. Mastrogiacomo dimostra, in modo convincente, che la doppia dottrina può avere una duplice valenza: negativa se intesa come impostura religiosa messa in atto per soggiogare, terrorizzare il popolo; positiva se la si considera come uno strumento tattico per proteggere i filosofi e la filosofia.

Non ufficialmente riconosciuto dagli Encyclopédistes (per ovvie ragioni di censura) che riprendono vari passi dei suoi libri offuscandone il nome, Boureau-Deslandes è un vero e proprio anticipatore dei tempi. Critica la società senza mai prescindere dalla fiducia nei confronti della ragione umana e nelle possibilità dell'uomo d'impiegarla per il bene della collettività, come nei suoi testi dedicati alla Marina. Il ritratto di BoureauDeslandes proposto da Elisabetta Mastrogiacomo è davvero affascinante e la sua ricostruzione degna della massima attenzione. 